\title{
Histopathological Profile of Orbito-ocular Lesions at Tertiary Hospital in Northern Malawi
}

\section{CURRENT STATUS: POSTED}

Research Square

Frank Watson Sinyiza

Mzuzu Central Hospital

frasinyiza@yahoo.comCorresponding Author

ORCiD: https://orcid.org/0000-0002-5009-4012

Alfred Kayira

Mzuzu Central Hospital

Master R.O. Chisale

Mzuzu Central Hospital, Mzuzu University

Chikondi Sharon Chimbatata

Mzuzu Central Hospital

Paul Uchizi Kaseka

Mzuzu Central Hospital

Pocha Samuel Kamudumuli

University Research Company, (URC)- Malawi Project

Tsung-Shu Joseph Wu

Pingtug Christian Hospital

Balwani Chingatichifwe Mbakaya

St John's Institute for Health

DOI:

$10.21203 / \mathrm{rs} .2 .22129 / \mathrm{v} 1$

SUBJECT AREAS

Ophthalmology

KEYWORDS

Orbito-ocular tumours, squamous cell carcinoma, Retinoblastoma 
Abstract

Background

Orbito-ocular lesions are common cause of morbidity and mortality in our population yet, there is paucity of data on their pattern which is crucial for developing an effective strategy for prevention, timely detection and management. This study sought to describe the burden and histopathological pattern of orbito-ocular lesions at Mzuzu Central Hospital (MCH) over a period of five years (July 2013 to June 2018).

\section{Methods}

A retrospective review of the clinicopathological profile of orbito-ocular lesions diagnosed at MCH was done. Demographic, clinical and histopathological data was obtained from original histology reports. Data analysis was conducted using Stata, version 13.0 (Stata Corp. LP, College Station, TX, United States of America). Descriptive analyses were performed to summarize patients' sociodemographic and clinical characteristics, and histopathological analysis results.

\section{Results}

Two hundred and fourteen (214) patients' records of orbito-ocular lesions were reviewed. Patients were predominantly females $60.3 \%$. The overall mean age was $34.81 \pm 15.93$ years. Conjunctiva was the most common site of orbito-ocular lesion accounting for $65.0 \%$ of the cases. This was followed by lid and adnexa (16.4\%) and intraocular lesions (9.3\%). Malignant lesions were the most prevalent (39.3\%), followed by degenerative conditions ( $25.2 \%)$, other benign lesions $(15.0 \%)$, Conjunctival Intraepithelial Neoplasia (CIN) (8.4\%), pyogenic and inflammatory conditions (8.4\%). The burden of cancer among males was $45.9 \%$ while in female was $34.9 \%$. Malignant lesions were common in HIV infected patients $64.1 \%$. There was bimodal distribution of orbito-ocular malignancies, one in the first decade of life and the other in third and fourth decade of life. Among cancers cases (84), squamous cell carcinoma, retinoblastoma, Kaposi Sarcoma and lymphoma contributed to $82.1 \%, 8.3 \%, 2.4 \%$ and $1.2 \%$ respectively. Kaposi sarcoma was found only in patient with HIV infection.

\section{Conclusion}

Cancer constituted a substantial proportion of orbito-ocular lesions in our study population with 
squamous cell carcinoma being the most common malignancy in adults and retinoblastoma in children. Degenerative disease contributed a high proportion of non-malignant lesions. Therefore, there is need for appropriate strategies to improve preventive, diagnostic and management capacity for orbito-ocular lesions at $\mathrm{MCH}$.

Full Text

Due to technical limitations, full-text HTML conversion of this manuscript could not be completed. However, the manuscript can be downloaded and accessed as a PDF.

Figures

Specimen is cut into $3-5 \mathrm{~mm}$ slices put in the cassette and the lid is covered.

Cassette is placed in a container of an automatic tissue processor. There are 12 containers each containing different reagents. The tissue moves from one to the other through all twelve. This process takes 24 hours.

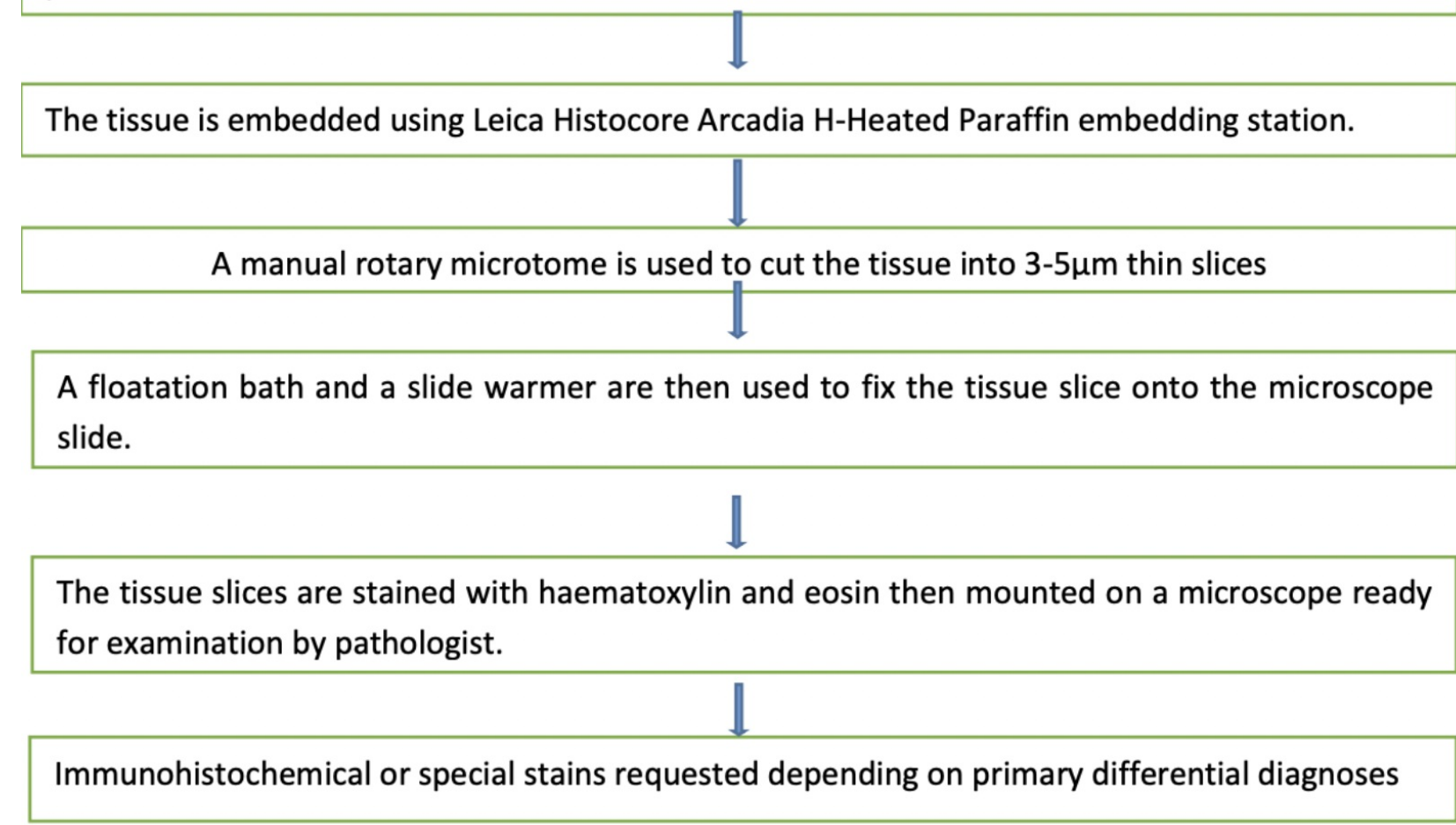

Figure 1

Processes involved in specimen processing at $\mathrm{KCH} / \mathrm{UNC}$ laboratory 